JAMP: Jurnal Adminitrasi dan Manajemen Pendidikan

Volume 3 Nomor 3 September 2020, Hal : 272-282

Tersedia Online di http://journal2.um.ac.id/index.php/jamp/

ISSN 2615-8574 (online)

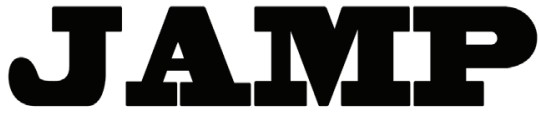

JURNAL ADMINISTRASI DAN MANAJEMEN PENDIDIKAN

\title{
DEBAT MORAL SEBAGAI UPAYA MENINGKATKAN INTEGRITAS KEPALA SEKOLAH
}

\author{
Ibrahim Bafadal \\ Juharyanto \\ Ahmad Nurabadi \\ Imam Gunawan
Universitas Negeri Malang, Jalan Semarang 5 Malang 65145
ibrahim.bafadal.fip@um.ac.id

\begin{abstract}
Integrity is the level of honesty and moral quality that a person possesses which is carried out consistently in everyday life. Integrity is the personality of a person who acts consistently and intact, both in word and in deed, in accordance with the values and code of ethics. Efforts to affirm the dedication and integrity of school principals and teachers are important to prepare the Indonesian generation for its era by continuing to update its competencies to provide the best educational services. Moral debate is used as an approach in increasing the integrity of school principals. Various matters related to education can be used as topics in the principal's moral debate. All of these topics must remain within the corridors of Indonesian nationality. National values are the main thing to improve the quality of school education through the leadership of the school principal. This is expected to foster the love of the country to students.
\end{abstract}

Keywords: integrity, principal, moral debate

\begin{abstract}
Abstrak: Integritas merupakan tingkat kejujuran dan kualitas moral yang dimiliki seseorang yang dilakukan secara konsisten dalam kehidupan sehari-hari. Integritas merupakan kepribadian seseorang yang bertindak secara konsisten dan utuh, baik dalam perkataan maupun perbuatan, sesuai dengan nilai-nilai dan kode etik. Upaya meneguhkan dedikasi dan integritas kepala sekolah dan guru menjadi hal penting untuk menyiapkan generasi Indonesia masuk ke zamannya dengan tetap memperbaharui kompetensi untuk memberikan layanan pendidikan terbaik. Debat moral digunakan sebagai pendekatan dalam meningkatkan intregitas kepala sekolah. Berbagai hal yang terkait dengan pendidikan dapat dijadikan topik dalam debat moral kepala sekolah. Semua topik tersebut harus tetap berada dalam koridor kebangsaan Indonesia. Nilai-nilai kebangsaan menjadi hal utama untuk meningkatkan mutu pendidikan sekolah melalui kepemimpinan kepala sekolah. Hal ini diharapkan dapat menumbuhkan nilai cinta tanah air kepada siswa.
\end{abstract}

Kata kunci: integritas, kepala sekolah, debat moral

Berdasarkan sudut pandang atau dimensi apapun dalam perkembangan peradaban selama ini, disepakati atau tidak, integritas merupakan standar tertinggi suatu kepemimpinan (McDowall, 2019; Gunawan, 2017a). Keberhasilan suatu organisasi, termasuk organisasi pendidikan sangat ditentukan oleh kualitas integritas kepala sekolah sebagai pimpinan sekolah. Hancurnya suatu lembaga, apapun bentuk dan bidang garapannya, sangat ditentukan oleh aspek integritas pimpinan dalam melaksanakan tugas kepemimpinannya. Kasus-kasus tentang lemahnya integritas dan dampaknya terhadap mutu dan keberterimaan sekolah oleh masyarakat yang terjadi selama ini, membuktikan bahwa integritas merupakan unsur terpenting yang menentukan kredibilitas dan kualitas sekolah. Debat moral merupakan salah satu model yang dapat digunakan dalam meningkatkan integritas kepala sekolah. Integritas merupakan hal penting dalam penyelenggaraan pendidikan. 
Debat merupakan kegiatan yang mengadu argumen orang atau kelompok orang untuk menentukan argumen mana yang baik dan didukung oleh satu pihak serta ditolak oleh pihak lain. Debat merupakan kegiatan yang membahas tentang suatu materi atau problematika dengan cara tukar-menukar pendapat suatu masalah. Kegiatan debat dilakukan bukan tanpa tujuan, tentu ada hal yang ingin dicapai oleh semua pihak. Adapun beberapa tujuan dan manfaat diadakannya debat adalah: (1) memantapkan pemahaman dari suatu materi yang diperdebatkan; (2) membantu untuk meningkatkan kemampuan dalam merespons suatu masalah yang diperdebatkan; (3) melatih diri untuk bersikap kritis pada setiap materi yang diperdebatkan; (4) melatih untuk mematahkan pendapat dari lawan debat; dan (5) melatih keberanian atau mental orang dalam mengemukakan pendapat di muka umum. Debat adalah suatu pembahasan atau tukar pendapat tentang suatu pokok masalah dimana setiap peserta memberikan alasan untuk mempertahankan pendapatnya.

Kepemimpinan yang konsisten menunjukkan keteladanan dalam mempengaruhi orang lain (Gunawan, 2017; Sudharta, dkk., 2017), yang berarti memberikan daya dorong untuk memotivasi dirinya dalam membangun integritas, memahami secara mendalam prinsip dalam menumbuhkan integritas (Kusumaningrum, dkk., 2018a; Gunawan, 2012). Pemimpin harus memahami arti dan makna integritas dengan mengaplikasikannya dalam kehidupan sehari-hari. Caranya adalah dengan mendorong diri dan orang lain untuk menggunakan pikiran dalam memahami unsur-unsur yang memiliki makna sebagai suatu proses meningkatkan motivasi diri dalam rangka membangun kepercayaan diri dan keyakinan diri sebagai acuan agar seorang pemimpin dapat menjadi pioner kemajuan sekolah.

Kesadaran terhadap pentingnya integritas tersebut, menggiring seluruh organisasi untuk meletakkan aspek integritas sebagai program prioritas (Sobri, dkk., 2018; Pertiwi, dkk., 2018; Gunawan, 2017b; Kusumaningrum, dkk., 2016; Gunawan, 2016), walaupun dalam wujud yang berbeda-beda. Di Indonesia, pada tingkat pusat dibentuk suatu badan yang disebut dengan Komisi Pemberantasan Korupsi. Pada tingkat sekolah, khususnya di setiap penyelenggaran ujian, selalu ditekankan aspek kejujuran, bahkan wajib menandatangani pakta integritas. Kepala sekolah yang memiliki integritas, etika, dan nilai akan menjadi pemimpin pendidikan yang andal (Bafadal, dkk., 2018; Gunawan, 2018; Sudharta, dkk., 2017; Kusumaningrum, dkk., 2019). Integritas adalah nilai universal yang menjadi tolak ukur kepemimpinan berbagai bidang. Integritas menjadi ukuran moral yang universal untuk mengetahui nilai dan perilaku seorang pemimpin.

Pilihan tema yang akan dibahas dalam debat moral menjadi penting untuk diidentifikasi, agar nantinya pada saat dilaksanakan debat moral oleh kepala sekolah, tema debat moral benar-benar dapat dipahami oleh peserta debat dan hasil pembahasan dalam forum debat tersebut juga akan menghasilkan suatu formula penyelesaian masalah yang tepat dan tepat terhadap permasalahan yang dibahas. Artikel ini memiliki tujuan mengidentikasi tema-tema yang dapat dijadikan bahan bahasan pada debat moral kepala sekolah. Tema-tema tersebut nantinya dapat dipilih sesuai dengan kondisi pada saat dilaksanakan debat moral kepala sekolah.

\section{METODE}

Penelitian ini menggunakan pendekatan kualitatif. Teknik pengumpulan data adalah dokumentasi, yaitu dengan mencari berita online yang terkait dengan pendidikan. Pencarian berita dilakukan rentang bulan Maret sampai dengan Agustus 2019 dari berbagai media massa online. Media online yang dipilih sebagai sumber berita adalah media online yang memiliki kredibilitas dalam bidang jurnalistik. Hal ini sebagai langkah untuk menghindari adanya berita yang tidak benar (hoaks). Berbagai berita tersebut diklasifikasikan menjadi dua, yaitu: moral dan amoral. Berita moral adalah berita yang berisi hal-hal baik dalam bidang pendidikan. Sedangkan berita amoral adalah berita yang berisi hal-hal kurang baik dalam bidang pendidikan. Berbagai berita tersebut selanjutnya ditentukan dalam tema-tema substansi pendidikan yang lebih spesifik. Langkah-langkah yang dilakukan dalam melaksanakan penelitian ini diilustrasikan pada Gambar 1. Artikel ini merupakan bagian penelitian PNBP UM 2019. 


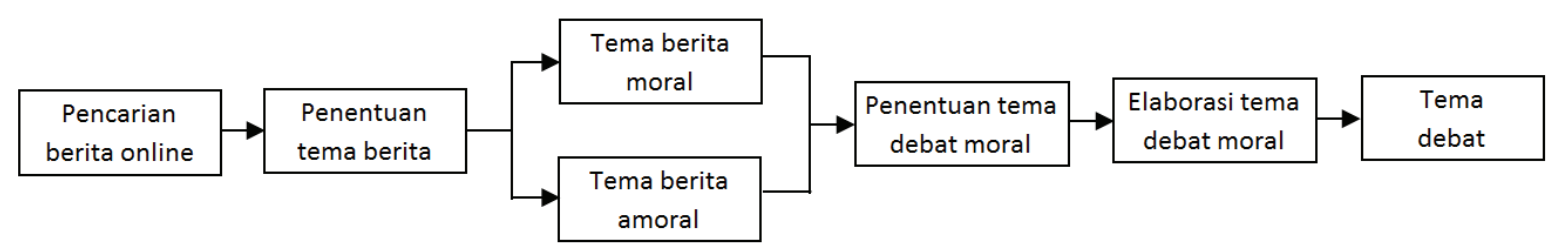

Gambar 1 Langkah-langkah Pelaksanaan Penelitian

\section{HASIL}

Tak dapat dipungkiri bidang pendidikan juga tidak terlepas dari problematika. Berbagai problematika tersebut tentu menuntut penyelesaian yang tepat, agar pendidikan tidak kehilangan ruhnya. Proses menemukan solusi tersebut juga tidak mudah, memerlukan proses yang terkadang melelahkan. Oleh sebab itu, musyawarah perlu dikedepankan dalam mencari solusi permasalahan tersebut. Debat moral menjadi salah satu model yang dapat digunakan dalam meningkatkan integritas kepala sekolah. Integritas kepala sekolah akan diuji ketika sekolah mengalami masalah. Kredibilitas kepala sekolah akan diuji dengan kemampuannya menyelesaikan masalah secara bijak. Mengacu pada langkah-langkah penelitian (Gambar 1) diperoleh tema-tema yang dapat dijadikan tema debat moral kepala sekolah. Sumber berita media online yang dijadikan dasar penentuan tema debat moral disajikan pada Tabel 1. Berdasarkan pencarian berita di media online tersebut diperoleh sepuluh tema. Berikut ini akan diuraikan tema-tema debat moral kepala sekolah.

\section{Mutu Sumber Daya Manusia}

Mutu sumber daya pendidikan (SDM) menjadi topik yang selalu menarik untuk dibahas dalam forum seminar pendidikan. Tuntutan mutu SDM pendidikan menjadi bahasan yang mengemuka dari masa ke masa. Standar pendidikan yang ditentukan oleh pemerintah menjadi tolak ukur menentukan pendidikan. Pengukuran mutu pendidikan pun akan terus mengalami perkembangan. Mutu pendidikan sekolah diukur dengan akreditas sekolah, dan berbagai sertifikasi yang didapat diajukan sendiri oleh sekolah, seperti International Standard Organization (ISO). Mutu kepala sekolah dapat diukur dengan kinerja, kompetensi, kepemimpinan, manajerial, dan manajemen sekolah. Mutu guru dapat diukur dari kinerja mengajar, pengembangan keprofesian berkelanjutan, dan kompetensi. Mutu tenaga administrasi sekolah (TAS) dapat diukur dari layanan administrasi, kepuasan layanan, dan kompetensi.

\section{Siswa Kreatif}

Kreativitas merupakan kemampuan yang harus dimiliki oleh peserta didik. Apalagi pada masa saat ini, perkembangan terus berjalan dengan cepat. Kreativitas merupakan cerminan kemampuan berpikir orang dalam menciptakan sesuatu hal dalam menyelesaikan masalah. Kemampuan berpikir peserta didik menjadi modal dasar untuk meningkatkan kreativitas. Persoalan yang terjadi di masyarakat memerlukan daya nalar yang tinggi untuk menyelesaikan permalasahan tersebut dengan tepat dan cepat. Peserta didik dihadapkan pada permasalahan yang terjadi di masyarakat agar ia dapat berkontribusi positif dalam menyelesaikan permasalahan tersebut.

\section{Efisiensi Keuangan}

Sumber daya yang dimiliki oleh sekolah bersifat terbatas, termasuk keuangan sekolah. Oleh sebab itu, efisiensi keuangan menjadi hal yang krusial untuk dilakukan sekolah. Keuangan sekolah dimanfaatkan untuk kepentingan pendidikan dan pembelajaran, investasi, dan pengembangan profesi. Sekolah harus memiliki skala prioritas kegiatan mana yang harus didanai. Sekolah harus menghitung dengan rinci keperluan dana setiap programnya dan juga menyesuaikan dengan upaya pencapaian tujuan sekolah. Sumber dana dari luar sekolah yang dapat dipertanggungjawabkan bisa diusahakan sekolah untuk membantu pelaksanaan program. Sekolah mulai dari menyusun Rencana Kegiatan dan Anggaran Sekolah (RKAS) harus melakukan analisis terhadap alokasi pendanaan dan kegiatan yang akan dilakukan oleh sekolah. 


\section{Sekolah Anti Korupsi}

Korupsi sejak dasawarsa saat ini menjadi momok dalam sistem pemerintahan Indonesia. Sebagai lembaga mengedepankan etika dan moral, sekolah memiliki tanggung jawab moral mendidik dan menyiapkan peserta didiknya menjadi pribadi-pribadi yang baik, jujur, dan berintegritas. Agar nantinya ketika sudah dewasa dan memiliki kewenangan kekuasaan, baik pada sektor swasta dan pemerintahan, ia tidak melakukan korupsi. Sikap antikorupsi harus ditanamkan sejak dini, dan sekolah memiliki tanggung jawab untuk itu. Sikap antikorupsi ditunjukkan dengan perilaku seseorang dengan menolak yang bukan haknya, tidak memanfaatkan jabatan atau kewenangannya, dan memiliki integritas tinggi dalam melaksanakan tugas. Dewasa ini sekolah merancang program yang mendukung sekolah antikorupsi, seperti kantin kejujuran, sekolah bebas gratifikasi, dan bekerja dengan dedikasi tinggi.

\section{Perpustakaan Sekolah}

Berbagai survei yang dilakukan oleh lembaga independen, baik dalam maupun luar negeri, menunjukkan daya baca dan kemampuan literasi orang Indonesia termasuk dalam kategori kurang baik. Hasil survei itu tidak perlu diperdepatkan lebih panjang lagi, namun perlu sebuah langkah konkret dari berbagai elemen bangsa, agar Indonesia meningkat daya baca dan kemampuan literasinya. Sekolah melalui perpustakaan yang dimiliki harus berupaya secara aktfi dan masif untuk meningkatkan daya baca dan kemampuan literasi para peserta didiknya. Perpustakaan sekolah yang bermutu adalah perpustakaan yang benar-benar dimanfaatkan untuk kegiatan pendidikan dan pembelajaran. Perpusatakaan sekolah menjadi pintu masuk pertama dalam meningkatkan kecintaan peserta didik terhadap kebiasaan membaca.

\section{Sekolah Siaga Bencana}

Wilayah Indonesia memiliki potensi tinggi terjadinya bencana. Bencana dapat terjadi sewaktuwaktu. Oleh sebab itu, kewaspadaan terhadap bencana merupakan hal penting agar dapat meminimalisasi kerugian akibat terjadinya bencana. Sekolah siaga bencana merupakan konsep yang saat lazim diusung oleh sekolah dalam rangka menghadapi bencana. Program siaga bencana yang dapat dilaksanakan oleh sekolah adalah simulasi bencana, pelatihan pertolongan pertama, dan pelatihan keselamatan kerja. Selain itu, sekolah secara periodik juga harus mengecek kondisi fisik sekolah untuk menjamin keselamatan para warga sekolah. Sekolah dapat memberdayakan Palang Merah Remaja (PMR) untuk membantu program sekolah siaga bencana. Anggota PMR dapat dijadikan kader sekolah siaga bencana yang memiliki tugas membantu sekolah secara operasional pelaksanaan program sekolah siaga bencana.

\section{Sekolah Ramah Anak}

Selain keselamatan dari sisi fisik, sekolah juga harus memberikan jaminan kepada para peserta didiknya agar belajar dengan senang. Artinya lingkungan fisik dan nonfisik sekolah harus ramah terhadap peserta didik. Sekolah ramah anak adalah sekolah yang dapat membuat peserta didik merasa nyaman, senang, dan aman belajar di sekolah. Beberapa indikator sekolah ramah anak adalah terjaganya kondisi psikis peserta didik, lingkungan yang asri, risiko kecelakaan yang kecil, dan adanya perlindungan kepada peserta didik dari ancaman fisik dan psikisnya. Terwujudnya sekolah ramah anak menjadi variabel terlaksananya pembelajaran yang selalu memperhatikan kondisi peserta didik, baik dari sisi psikologis dan lingkungan belajarnya.

\section{Perlindungan Profesi Guru}

Guru sebagai profesi harus memiliki sistem perlindungan profesi yang jelas, sebab guru pada saat melaksanakan tugasnya akan bersentuhan dengan berbagai ragam bidang. Perlindungan profesi guru ini terutama dari sisi hukum. Guru dalam menjalankan profesinya mengikuti kaidah norma yang berlaku. Norma-norma ini menjadi acuan dan landasan bagi para guru untuk mengajar, berinteraksi dengan orang tua, menjalin kerjasama dengan masyarakat, dan pengembangan profesinya. Perlindungan profesi guru yang dimaksud di sini adalah untuk meminimalisasi adanya tuntutan hokum kepada guru yang di luar batas kewajaran norma. 


\section{Moral Pendidikan}

Pendidikan sebagai mercusuar membangun moral dan etika bangsa memiliki tugas dalam mengembangkan karakter bangsa. Moral pendidikan adalah ukuran norma dan perilaku yang dapat dijadikan indikator baik buruknya perilaku seseorang. Perilaku kepala sekolah, guru, TAS, dan para peserta didiknya adalah cerminan moral pendidikan. Sekolah merupakan wahana mendidik moral peserta didik. Oleh sebab itu, peserta didik harus dikenalkan kepada sumber dan nilai yang membangun moral, seperti agama, budaya, adat istiadat, dan hukum. Hal ini selaras dengan program yang dicanangkan oleh pemerintah, yaitu pendidikan karakter. Moral dan pendidikan karakter dapat selaraskan dengan program penumbuhan budi pekerti peserta didik yang merupakan cerminan moral dan perilaku peserta didik serta warga sekolah lainnya.

\section{Komite Sekolah}

Komite sekolah adalah lembaga yang membantu sekolah dalam mengembangkan mutu sekolah. Peran komite sekolah sangat kuat dalam penyelenggaraan pendidikan sekolah, yaitu sebagai pemberi pertimbangan, pendukung, pengontrol, dan mediator sekolah. Komite sekolah memiliki posisi yang strategis dalam meningkatkan mutu pendidikan sekolah. Komite sekolah merupakan lembaga mandiri yang menjadi wadah peran serta masyarakat dalam meningkatkan pemerataan, mutu, dan efisiensi pengelolaan pendidikan sekolah.

\section{Tabel 1 Sumber Berita Moral dan Amoral}

\begin{tabular}{|c|c|}
\hline No & Sumber Berita \\
\hline A & Moral \\
\hline 1 & $\begin{array}{l}\text { https://suryamalang.tribunnews.com/2017/03/08/simak-ini-daftar-guru-dan-kepala-sekolah-terbaik- } \\
\text { di-kota-malang-tahun-ini }\end{array}$ \\
\hline 2 & $\begin{array}{l}\text { http://Ippks.kemdikbud.go.id/id/kabar/kisah-kepala-sekolah-rusdi-mengubah-sekolah-kolaps- } \\
\text { menjadi-sekolah-berprestasi-di-kota-malang }\end{array}$ \\
\hline 3 & $\begin{array}{l}\text { https://suryamalang.tribunnews.com/2018/04/23/guru-smp-islam-sabillilah-kota-malang-sabet-juara- } \\
\text { guru-berprestasi-dari-dinas-pendidikan }\end{array}$ \\
\hline 4 & https://diknas.malangkota.go.id/pipit-gupres-prestasi-asal-sdn-tunjungsekar-3-malang/ \\
\hline 5 & $\begin{array}{l}\text { https://news.detik.com/berita-jawa-timur/d-3656405/dua-pelajar-ini-ciptakan-tinta-spidol-dari-daun- } \\
\text { jambu-biji }\end{array}$ \\
\hline 6 & $\begin{array}{l}\text { https://news.detik.com/berita-jawa-timur/d-4147893/masih-smp-pelajar-ponorogo-ciptakan-rompi- } \\
\text { untuk-bantu-tunanetra?tag_from=news_beritaTerkait }\end{array}$ \\
\hline 7 & $\begin{array}{l}\text { https://edukasi.kompas.com/read/2019/03/27/21514511/mendorong-praktik-baik-manajemen- } \\
\text { keuangan-sekolah-lewat-teknologi }\end{array}$ \\
\hline 8 & $\begin{array}{l}\text { https://edukasi.kompas.com/read/2018/11/06/16491021/kolaborasi-edutech-dan-fintech-mengurai- } \\
\text { masalah-biaya-pendidikan }\end{array}$ \\
\hline 9 & $\begin{array}{l}\text { https://www.republika.co.id/berita/nasional/pemprov-jabar/17/07/16/ot65kp-jawa-barat- } \\
\text { kembangkan-sekolah-berbudaya-lingkungan }\end{array}$ \\
\hline 10 & https://kumparan.com/@kumparannews/icw-buka-sekolah-antikorupsi-libatkan-guru-hingga-pns \\
\hline 11 & https://mediaindonesia.com/read/detail/46722-membangkitkan-literasi-lokal \\
\hline 12 & $\begin{array}{l}\text { https://news.okezone.com/read/2019/01/03/65/1999638/perpustakaan-berbasis-inklusi-sosial- } \\
\text { tingkatkan-kesejahteraan-masyarakat }\end{array}$ \\
\hline 13 & $\begin{array}{l}\text { https://news.detik.com/berita-jawa-timur/d-4346473/program-kantin-kejujuran-di-jatim-ada-pakta- } \\
\text { integritasnya-Iho }\end{array}$ \\
\hline 14 & $\begin{array}{l}\text { https://regional.kompas.com/read/2018/11/09/13301831/sekolah-siaga-bencana-upaya-sadar- } \\
\text { bencana-bpbd-luwu-utara }\end{array}$ \\
\hline 15 & $\begin{array}{l}\text { https://kumparan.com/beritaanaksurabaya/cegah-kekerasan-di-sekolah-surabaya-gagas-sekolah- } \\
\text { ramah-anak-1qs66uqh7uF }\end{array}$ \\
\hline
\end{tabular}




\begin{tabular}{|c|c|}
\hline No & Sumber Berita \\
\hline B & Amoral \\
\hline 1 & $\begin{array}{l}\text { https://news.detik.com/berita/d-4467898/pukul-guru-saat-mediasi-orang-tua-murid-di-mamuju- } \\
\text { diamankan-polisi?_ga=2.71143056.1880240852.1558505888-842557077.1558505888 }\end{array}$ \\
\hline 2 & https://www.jpnn.com/news/perbuatan-terlarang-kepala-sekolah-dan-siswinya-di-sebuah-rumah \\
\hline 3 & $\begin{array}{l}\text { https://regional.kompas.com/read/2019/02/01/17270241/terlibat-tawuran-yang-tewaskan-1-siswa-3- } \\
\text { pelajar-smk-diamankan-polisi }\end{array}$ \\
\hline 4 & $\begin{array}{l}\text { https://www.antaranews.com/berita/808922/inpektorat-ingatkan-sekolah-tak-buat-laporan-dana- } \\
\text { bos-fiktif }\end{array}$ \\
\hline 5 & $\begin{array}{l}\text { https://republika.co.id/berita/pendidikan/eduaction/pq53k5368/rendahnya-kompetensi-guru-jadi- } \\
\text { masalah-pendidikan-indonesia }\end{array}$ \\
\hline 6 & $\begin{array}{l}\text { https://www.jpnn.com/news/terkait-soal-un-sma-bocor-sanksi-dari-kemendikbud-dinilai-terlalu- } \\
\text { ringan }\end{array}$ \\
\hline 7 & $\begin{array}{l}\text { http://wartakota.tribunnews.com/2019/03/25/begini-nasib-sekolah-yang-kekurangan-komputer-saat- } \\
\text { selenggarakan-ujian-nasional }\end{array}$ \\
\hline 8 & $\begin{array}{l}\text { https://radarsolo.jawapos.com/read/2019/01/07/112177/kemampuan-guru-menulis-karya-tulis- } \\
\text { ilmiah-terganjal-waktu }\end{array}$ \\
\hline 9 & $\begin{array}{l}\text { https://kompas.id/baca/nusantara/2018/10/08/bendahara-komite-sekolah-gelapkan-dana-program- } \\
\text { indonesia-pintar/ }\end{array}$ \\
\hline 10 & $\begin{array}{l}\text { https://www.beritasatu.com/megapolitan/539263/korupsi-dana-bos-mantan-kepala-sekolah-sma-3- } \\
\text { depok-dibekuk }\end{array}$ \\
\hline 11 & $\begin{array}{l}\text { https://www.merdeka.com/peristiwa/guru-smpn-10-yogyakarta-mengaku-emosi-dan-spontan- } \\
\text { tendang-siswanya.html }\end{array}$ \\
\hline 12 & $\begin{array}{l}\text { https://news.detik.com/berita/d-4423678/fenomena-murid-tantang-guru-apakah-pendidikan-keras- } \\
\text { jadi-solusi }\end{array}$ \\
\hline 13 & https://edukasi.kompas.com/read/2012/07/24/05154075/ Kompetensi.Kepala.Sekolah.Masih.Rendah \\
\hline 14 & https://kalsel.antaranews.com/berita/40944/kemampuan-guru-dalam-menulis-masih-rendah \\
\hline 15 & $\begin{array}{l}\text { https://www.pikiran-rakyat.com/pendidikan/2019/05/11/guru-dan-tenaga-honorer-terancam-tak- } \\
\text { dapat-honorarium }\end{array}$ \\
\hline
\end{tabular}

\section{PEMBAHASAN}

Debat adalah argumen terstruktur. Dua pihak berbicara secara bergantian untuk mempertahankan argumen yang lazim didasarkan pada masalah topikal (SFU, 2019). Berbeda dengan argumen yang mungkin dimiliki oleh orang lain, masing-masing orang diberi waktu untuk berbicara dan setiap interupsi dikendalikan dengan hati-hati. Subyek perselisihan sering diatur sebelumnya sehingga seseorang mungkin harus mendukung pendapat yang biasanya tidak disetujui. Seseorang juga harus berdebat sebagai bagian dari tim, berhati-hati untuk tidak bertentangan dengan apa yang dikatakan orang lain di pihak sendiri. Berdebat adalah cara terbaik untuk meningkatkan keterampilan berbicara dan sangat membantu dalam memberikan pengalaman dalam mengembangkan argumen yang meyakinkan. Seseorang yang terpaksa berdebat dengan sudut pandang sendiri akan menyadari bahwa argumen seperti koin, selalu memiliki setidaknya dua sisi.

Ada beberapa keterampilan yang harus dimiliki seseorang dalam melakukan debat moral, yaitu: (1) gaya; (2) kecepatan; (3) nada; (4) volume; (5) kejelasan; (6) penggunaan catatan dan kontak mata; dan (7) konten (Kidd, 2017). Berikut ini akan diuraikan ketujuh keterampilan tersebut. Gaya adalah cara mengomunikasikan argumen. Ini adalah bagian paling dasar dari debat untuk dikuasai (Kidd, 2017). Konten dan strategi hanya bernilai sedikit kecuali seseorang mengirimkan materi dengan cara yang percaya diri dan persuasif. Kecepatan, sangat penting untuk berbicara dengan kecepatan yang cukup cepat untuk terdengar cerdas dan memberi seseorang waktu untuk mengatakan apa yang diinginkan, 
tetapi cukup lambat untuk mudah dimengerti. Nada, variasi nada inilah yang membuat terdengar menarik. Mendengarkan satu nada untuk seluruh presentasi itu membosankan (Kidd, 2017).

Volume, berbicara dengan keras kadang-kadang merupakan keharusan, tetapi sama sekali tidak perlu berteriak melalui setiap debat, terlepas dari konteksnya. Sama sekali tidak perlu berbicara lebih keras daripada volume di mana semua orang di ruangan itu dapat dengan nyaman mendengar. Berteriak tidak memenangkan debat. Berbicara terlalu pelan jelas merupakan malapetaka, karena tidak ada yang bisa mendengar. Kejelasan, kemampuan untuk secara ringkas dan jelas mengutarakan masalahmasalah kompleks adalah inti dari perdebatan. Alasan utama orang mulai terdengar tidak jelas biasanya karena mereka kehilangan "aliran pemikiran" yang membuat mereka terus berjalan. Penting juga untuk membuatnya tetap sederhana. Meskipun kata-kata yang panjang mungkin membuat seseorang terdengar pintar, mereka mungkin juga membuat seseorang tidak bisa dimengerti (SFU, 2019).

Penggunaan catatan dan kontak mata, catatan sangat penting, tetapi harus singkat dan terorganisir dengan baik agar efektif. Sama sekali tidak ada gunanya mencoba berbicara tanpa catatan. Tentu saja, catatan tidak boleh menjadi menonjol dan merusak kontak seseorang dengan audiens, juga tidak boleh dibaca dari kata demi kata. Kebanyakan orang membuat sketsa judul utama pidato mereka, dengan catatan singkat di bawah masing-masing. Saat menulis catatan untuk bantahan selama debat, biasanya lebih baik menggunakan selembar kertas terpisah, sehingga seseorang bisa mencatat rincian apa yang dikatakan pembicara lain dan kemudian mentransfer garis besar kasar ke catatan yang sebenarnya akan digunakan. Kontak mata dengan audiens sangat penting, tetapi terus ubah pandangan. Tidak ada yang suka ditatap. Konten adalah apa yang sebenarnya seseorang katakan dalam debat. Argumen yang digunakan untuk mengembangkan kasus pihak diri sendiri dan membantah pihak lawan. Informasi tentang konten adalah gambaran umum tentang apa yang diharapkan saat berdebat.

Moralitas adalah sarana untuk mencapai tujuan. Biasanya tujuan itu adalah kebaikan. Seseorang berperilaku dengan cara yang mencapai kebaikan. Moralitas adalah peraturan tentang perilaku (Ashmitas, 2018). Oleh karena itu, moralitas adalah sarana untuk mencapai kebaikan melalui pengaturan perilaku. Tetapi moralitas tergantung pada nilai-nilai. Tidak ada nilai universal. Agama, budaya, individu, dan negara memiliki nilai yang sangat berbeda. Bisa dikatakan bahwa orang harus menghargai atribut yang menonjolkan tujuan organisasi. Tetapi hanya benda-benda yang diciptakan yang memiliki tujuan.

Garpu memiliki tujuan, televisi memiliki tujuan, dan telepon memiliki tujuan. Tetapi manusia tidak dibuat, ia berevolusi. Karena itu, manusia tidak memiliki tujuan, tujuan yang melekat yang membuat moralitas objektif menjadi tidak mungkin. Karena kurangnya standardisasi ini, satu-satunya tempat yang tepat untuk moralitas adalah di rumah tangga atau tempat ibadah. Hal terakhir yang dibutuhkan adalah mendelegasikan tanggung jawab moralitas kolektif kepada masyarakat secara luas. Masyarakat membiarkan televisi, internet, dan sekolah membesarkan peserta didik dan mereka diharapkan lebih baik daripada sebelumnya secara moral dan integral (Ashmitas, 2018; Sultoni, dkk., 2018; Ullah, 2018). Masyarakat harus perlu memegang teguh moralitas (Gunawan, 2015; Bafadal, dkk., 2019; Sultoni, dkk., 2019; Gunawan, 2011).

Pancasila merupakan sumber moral kehidupan berbangsa dan bernegara. Kesadaran akan nilainilai moral dari warga sekolah perlu dibangun secara terus menerus. Sekolah perlu mengetahui tahapan perkembangan moral peserta didik. Setiap perkembangan moral peserta didik berbeda (Gunawan \& Sulistyoningrum, 2013), sehingga semua nilai moral yang terkandung dalam Pancasila harus terinternalisasi dalam diri peserta didik (Argadinata \& Gunawan, 2019). Nilai-nilai moral Pancasila yang memiliki 36 butir harus dipahami oleh semua warga sekolah, berdasarkan tingkat pemahaman dan kesadaran terhadap nilai-nilai tersebut.

Berbagai hal yang terkait dengan pendidikan dapat dijadikan topik dalam debat moral kepala sekolah. Persoalan yang dapat dijadikan topik adalah: kepemimpinan pendidikan, supervisi pendidikan, administrasi pendidikan, manajemen pendidikan, kebijakan pendidikan, keuangan pendidikan, sarana prasarana pendidikan, partisipasi masyarakat, perkembangan peserta didik, atau kurikulum. Semua topik tersebut harus tetap berada dalam koridor kebangsaan Indonesia. Nilai-nilai kebangsaan menjadi hal utama untuk meningkatkan mutu pendidikan sekolah melalui kepemimpinan kepala sekolah. Hal ini 
diharapkan dapat menumbuhkan nilai cinta tanah air kepada siswa. Sehingga perlu sebuah kajian yang mengupas bidang-bidang tersebut secara terpadu. Tak jarang kegagalan organisasi karena manajemen yang kurang baik (Nurabadi, dkk., 2018; Gunawan \& Benty, 2017), artinya perencanaan, pengorganisasian, penggerakkan, dan pengawasan tidak dilaksanakan dengan tepat atau malah menyimpang. Tanpa adanya manajemen pendidikan yang mapan dan dapat diterapkan, penyelenggaraan pendidikan juga akan berjalan tidak optimal dan tepat serta berpengaruh juga terhadap pencapaian tujuan pendidikan yang tidak optimal.

Proses manajemen pendidikan merupakan jantung penyelenggaraan pendidikan agar berjalan dengan lancar, tepat, dan optimal. Berdasarkan hal tersebut seorang manager pendidikan sudah barang tentu harus menguasai dan mampu mengimplementasikan manajemen pendidikan. Manajemen pendidikan dalam hal ini bukan berarti sekarang "tidak hidup" namun perlu adanya penataan yang terpadu dan komprehensif terhadap bidang manajemen pendidikan serta bidang-bidang lain yang bergayut dengan manajemen pendidikan secara berkelanjutan agar manajemen pendidikan menjadi aktivitas yang harus dan patut diperhatikan. Sekarang banyak kalangan membicarakan manajemen pendidikan. Setelah itu perlu adanya upaya internalisasi juga secara masif kepada stakeholders tentang proses manajemen pendidikan.

Internalisasi merupakan proses memasukkan, membiasakan orang agar berperilaku sesuai dengan idealnya, jika tidak melakukan maka seperti ada yang kurang di dalam dirinya. Internalisasi merupakan penghayatan terhadap suatu ajaran, doktrin, atau nilai sehingga merupakan keyakinan dan kesadaran akan kebenaran doktrin atau nilai yang diwujudkan dalam sikap dan perilaku. Sehingga setiap pengelola pendidikan mengimplementasikan dan menghayati proses manajemen pendidikan dalam rangka mendukung pencapaian tujuan pendidikan (Kusumaningrum, dkk., 2016; Benty \& Gunawan, 2015; Gunawan, 2014; Kusumaningrum, dkk., 2018b).

Jika mengacu pada substansi manajemen pendidikan, maka kajian yang dapat dijadikan tema debat moral kepala sekolah adalah: perencanaan pendidikan; pengelolaan pendidikan; pengawasan, monitoring, dan evaluasi pendidikan; organisasi pendidikan; manajemen mutu terpadu; manajemen strategik; manajemen kurikulum dan pembelajaran; manajemen peserta didik; manajemen sumber daya manusia; manajemen sarana prasana; manajemen keuangan; manajemen layanan khusus; manajemen partisipasi masyarakat; manajemen perkantoran; dan kewirausahaan pendidikan. Kajian tentang supervisi pendidikan, kepemimpinan pendidikan, kebijakan pendidikan, pendidikan karakter, inovasi pendidikan, profesi pendidikan, dan teknologi pendidikan juga dapat menjadi tema debat moral kepala sekolah. Adanya debat moral kepala sekolah akan meningkatkan wawasan pengetahuan kepala sekolah pemula dalam memimpin penyelenggaraan pendidikan sekolah. Wawasan tersebut akan lebih bermakna manakala didukung dengan kinerja kepala sekolah, guru, dan staf sekolah yang andal.

Pendidikan moral baru-baru ini menikmati kebangkitan dalam pendidikan tinggi, dengan diterapkannya pendidikan karakter pada sistem pendidikan di Indonesia. Namun gagasan bahwa universitas memiliki tanggung jawab untuk mengajarkan etika dan moralitas kepada mahasiswa telah ditanggapi dengan skeptisisme, kecurigaan, dan bahkan penolakan langsung baik dari dalam maupun luar akademi (Kiss \& Euben, 2010). Dalam koleksi ini, sarjana filsafat, politik, dan agama terkenal memperdebatkan peran etika di universitas, menyelidiki apakah universitas harus secara proaktif mengembangkan moralitas dan etika, apa yang diperlukan dalam pengajaran etika, dan apa yang harus dicapai oleh pendidikan moral. Esai dengan cepat membuka pertanyaan yang lebih luas tentang tujuan pendidikan universitas dalam masyarakat modern.

Kiss \& Euben (2010) mensurvei sejarah etika dalam pendidikan tinggi, kemudian terlibat dengan tulisan terbaru yang provokatif di mana ia berpendapat bahwa universitas tidak boleh terlibat dalam pendidikan moral. Hauerwas menanggapi dengan menawarkan perspektif teologis tentang tujuan universitas (Carnegie Foundation for the Advancement of Teaching, 2012). Kontributor melihat tempat politik dalam pendidikan moral; menyarankan bahwa badan siswa multikultural yang semakin beragam adalah sumber daya untuk pengajaran etika; dan menunjukkan bagaimana perdebatan tentang pendidikan kewarganegaraan di sekolah-sekolah dasar negeri memberikan pelajaran berharga untuk pendidikan 
tinggi. Hal yang lain merefleksikan kebajikan dan karakter yang harus dipupuk oleh pendidikan moral pada siswa - seperti kejujuran, toleransi, dan integritas - dan cara pelatihan etis secara formal dan informal terjadi di kampus-kampus saat ini, dari ruang kelas hingga lapangan basket. Perdebatan pendidikan moral adalah kontribusi penting untuk diskusi berkelanjutan tentang peran dan evolusi pendidikan etika di universitas seni liberal modern.

Prosesi debat di mana tim memperdebatkan pertanyaan yang disiapkan di luar forum, membantu memajukan dua tujuan yang harus dicapai oleh peserta debat, partisipasi peserta debat di setiap sesi akan meningkatkan pemikiran kritis dan analisis masalah pendidikan (Oros, 2007). Topik yang dibahas pada debat pendidikan meliputi perbedaan dalam format debat dan persiapan untuk berbagai tingkatan dan ukuran kelas; bagaimana mengakomodasi peserta dari berbagai kemampuan melalui manajemen tim dan peran yang efektif; pilihan penilaian / metode evaluasi; dan pendekatan untuk melibatkan seluruh kelas dalam latihan pembelajaran aktif ini. Evaluasi manfaat pendekatan juga diberikan berdasarkan analisis sistematis dari evaluasi peserta dan pengamatan komparatif dari penulis dan instruktur lain yang telah menggunakan pendekatan tersebut.

Perdebatan yang meminta pihak afirmatif untuk memperdebatkan perubahan dalam cara kerja setiap aspek dunia sering digambarkan sebagai "debat kebijakan". Perdebatan semacam itu mengharuskan afirmatif untuk menyajikan model sebagai bagian dari definisi mereka. Model hanyalah garis besar dari berbagai perubahan yang menurut afirmatif harus dilakukan. Sederhananya, model adalah kebijakan yang dianut oleh afirmatif. Berdebat membantu orang belajar tentang diri sendiri, berpikir, dan bagaimana mengambil sikap terhadap suatu masalah. Untuk mempersiapkan, pertimbangkan beberapa topik debat, isu, dan pertanyaan yang menarik untuk membantu merumuskan argumen yang kuat.

\section{SIMPULAN}

Kepala sekolah adalah aktor utama penyelenggaraan pendidikan dan memiliki peran penting dalam meningkatkan mutu pendidikan sekolah. Oleh sebab itu, kepala sekolah dituntut untuk memahami problematika pendidikan secara komprehensif. Pemahaman kepala sekolah terhadap problematika pendidikan didukung dengan kemampuan berpikir dan beragumen kepala sekolah. Berbagai problematika tersebut membutuhkan solusi, kebijaksanaan, dan kebijakan kepala sekolah agar dapat selesai secara tepat dan cepat, sehingga tidak mengakibatkan masalah baru. Berbagai masalah yang dapat dijadikan tema debat moral kepala sekolah adalah: (1) mutu sumber daya manusia; (2) siswa kreatif; (3) efisiensi keuangan; (4) sekolah anti korupsi; (5) perpustakaan sekolah; (6) sekolah siaga bencana; (7) sekolah ramah anak; (8) perlindungan profesi guru; (9) moral pendidikan; dan (10) komite sekolah.

\section{DAFTAR RUJUKAN}

Argadinata, H., \& Gunawan, I. 2019. The Leadership of Pancasila in Education: Foundation for Strengthening Student Characters in the Industrial Revolution Era 4.0. The 4th International Conference on Education and Management (COEMA 2019), Atlantis Press, hlm. 5-7.

Ashmitas, V. 2018. Moral Education in School is a Good Step? (Online), (https://www.debate.org/opinions/moraleducation-in-school-is-a-good-step), diakses 22 Maret 2020.

Bafadal, I., Juharyanto, Nurabadi, A., \& Gunawan, I. 2018. The Influence of Instructional Leadership, Change Leadership, and Spiritual Leadership Applied at Schools to Teachers' Performance Quality. Proceedings of the International Conference on Education and Technology (ICET 2018), Published by Atlantis Press, 285, 197-200.

Bafadal, I., Juharyanto, Nurabadi, A., \& Gunawan, I. 2019. Efforts to Improve the Integrity of the Principal with the Moral Debate Model. the 4th International Conference on Education and Management (COEMA 2019), Atlantis Press, hlm. 1-4.

Benty, D. D. N., \& Gunawan, I. 2015. Manajemen Hubungan Sekolah dan Masyarakat. Malang: Penerbit UM Press.

Carnegie Foundation for the Advancement of Teaching. 2012. Campus Life: In Search of Community. New Jersey: Princeton. 
Gunawan, I. 2011. Merekonstruksi Fitrah Pendidikan. Komunikasi, Majalah Kampus Universitas Negeri Malang Tahun 33 Nomor 276 September - Oktober 2011, hlm. 32.

Gunawan, I. 2012. Mengembangkan Karakter Bangsa Berdasarkan Kearifan Lokal. Prosiding Seminar Nasional Meretas Sekolah Humanis untuk Mendesain Siswa Sekolah Dasar yang Cerdas dan Berkarakter, PGSD FKIP Universitas Muhammadiyah Surakarta, hlm. 67-79.

Gunawan, I. 2014. Pengaruh Supervisi Pengajaran dan Kemampuan Guru Mengelola Kelas terhadap Motivasi Belajar Siswa. Ilmu Pendidikan: Jurnal Kajian Teori dan Praktik Kependidikan, 41(1), 44-52.

Gunawan, I. 2015. Values and Ethics in Educational Leadership: An Idea of Character Building of Students. Conference Proceedings Character Education in Indonesia Concepts and Applications in Primary Schools, PGSD IKIP PGRI MADIUN, hlm. 1-13.

Gunawan, I. 2016. Model of Educational Leadership in the Implementation of Curriculum 2013. Proceedings The 4th International Conference Language, Society, and Culture in Asian Contexts (LSCAC 2016) on Cultivating and Casting Asian Diversities: Empowering the Asians, hlm. 1109-1118.

Gunawan, I. 2017. Instructional Leadership Profile of Junior High School's Principal (A Case Study of Junior High School in Malang). International Research-Based Education Journal, 1(1), 64-68.

Gunawan, I. 2017a. Indonesian Curriculum 2013: Instructional Management, Obstacles Faced by Teachers in Implementation and the Way Forward. Proceeding 3rd International Conference on Education and Training (3rd ICET) 2017, Theme: Global and Local Based Education and Training, Published by Atlantis Press, hlm. 56-63.

Gunawan, I. 2017a. Instructional Management in Indonesia: A Case Study. Journal of Arts, Science \& Commerce, 8(1), 99-107.

Gunawan, I. 2018. Kepemimpinan Pendidikan: Suatu Pengantar: Malang: Universitas Negeri Malang, UM Press. Gunawan, I., \& Benty, D. D. N. 2017. Manajemen Pendidikan: Suatu Pengantar Praktik. Bandung: Alfabeta.

Gunawan, I., \& Sulistyoningrum, R. T. 2013. Menggali Nilai-nilai Keunggulan Lokal Kesenian Reog Ponorogo Guna Mengembangkan Materi Keragaman Suku Bangsa dan Budaya pada Matapelajaran IPS Kelas IV Sekolah Dasar. Premiere Educandum: Jurnal Pendidikan Dasar dan Pembelajaran, 3(1), 50-87.

Kidd, A. 2017. The Oxford Union Rough Guide to Debating: The English Speaking Union. Retrieved June 10, 2019, from http://www.britishdebate.com/resources/hb_oxfordguide.htm.

Kiss, E., \& Euben, J. P. 2010. Debating Moral Education: Rethinking the Role of the Modern University. Durham: Duke University Press.

Kusumaningrum, D. E., Sumarsono, R. B., \& Gunawan, I. 2017. Problematika Pemberdayaan dan Pengembangan Sumber Daya Manusia di Sekolah Menengah Pertama Berbasis Pesantren. Ilmu Pendidikan: Jurnal Kajian Teori dan Praktik Kependidikan, 2(2), 139-150.

Kusumaningrum, D. E., Sumarsono, R. B., \& Gunawan, I. 2018a. Teachers Empowerment of Pesantren-Based Junior High School East Java Province Indonesia. Journal of Social Sciences and Humanity Studies, 4(3), 29-33.

Kusumaningrum, D. E., Sumarsono, R. B., \& Gunawan, I. 2018b. Empowering the Principal of Boarding HouseBased Junior High School in East Java Province Indonesia. Proceeding 3rd International Conference on Education Management and Administration (CoEMA 2018), Published by Atlantis Press, 269, 147-151.

Kusumaningrum, D. E., Sumarsono, R. B., \& Gunawan, I. 2019. Budaya Sekolah dan Etika Profesi: Pengukuran Pemberdayaan Sumber Daya Manusia Sekolah dengan Pendekatan Soft System Methodology. JAMP: Jurnal Administrasi dan Manajemen Pendidikan, 2(3), 90-97.

Kusumaningrum, D. E., Triwiyanto, T., \& Gunawan, I. 2016. Educational Management of Natural Disaster Response at Lapindo Mudsidoarjo East Java. Journal of Basic and Applied Scientific Research, 6(4), 1-8.

McDowall, R. D. 2019. Data Integrity and Data Governance: Practical Implementation in Regulated Laboratories. Cambridge: Royal Society of Chemistry.

Nurabadi, A., Sucipto, Juharyanto, \& Gunawan, I. 2018. The Implementation of Education Management Standards in the School Laboratory State University of Malang for Improving Educational Quality. Proceeding 3rd International Conference on Education Management and Administration (CoEMA 2018), Published by Atlantis Press, 269, 127-132.

Oros, A. L. 2007. Let's Debate: Active Learning Encourages Student Participation and Critical Thinking. Journal of Political Science Education, 3(3), 293-311.

Pertiwi, A. K., Cahyani, S. S. A., Diana, R. C., \& Gunawan, I. 2018. The Leadership of Kyai: A Descriptive Study. Proceeding 3rd International Conference on Education Management and Administration (CoEMA 2018), 269, 121-126. 
SFU. 2019. How to Debate. Retrieved June 10, 2019, from https://www.sfu.ca/cmns/130d1/HOWTODEBATE. htm.

Sobri, A. Y., Bafadal, I., Nurabadi, A., \& Gunawan, I. 2018. Development of Mentoring Modules Based on SelfReflection for Beginner Principal. Proceeding 3rd International Conference on Education Management and Administration (CoEMA 2018), Published by Atlantis Press, 269, 133-139.

Sudharta, V. A., Mujiati, M., Rosidah, A., \& Gunawan, I. 2017. Gaya Kepemimpinan Kepala Sekolah dalam Perspektif Psikologi. JMSP: Jurnal Manajemen dan Supervisi Pendidikan, 2(2), 109-123.

Sudharta, V. A., Mujiati, M., Rosidah, A., \& Gunawan, I. 2017. Gaya Kepemimpinan Kepala Sekolah dalam Perspektif Psikologi. Jurnal Manajemen dan Supervisi Pendidikan, 2(2), 109-123.

Sultoni, Gunawan, I., \& Sari, D. N. 2018. The Internalization of Character Values to Students: A Descriptive Study. Proceedings of the International Conference on Education and Technology (ICET 2018), Published by Atlantis Press, 285, 169-171.

Sultoni, Gunawan, I., \& Sari, D. N. 2019. Validity and Reliability of Character Education Internalization Instruments. The 4th International Conference on Education and Management (COEMA 2019), Atlantis Press, hlm. 245-249.

Ullah, K. I. M. D. 2018. Pentingnya Pendidikan Moral Zaman Now, (Online), (https://www.kompasiana.com/ke nizzul/5b4941f8f1334439d01302c2/pentingnya-pendidikan-moral-di-zaman-now), diakses 22 Maret 2020. 